\title{
A Non-Isokinetic Approach for Modeling Solid-State Transformations: Application to Crystallization of a Fe-B Amorphous Alloy
}

\author{
Yazhu Ma ${ }^{\dagger}$, Yubing Zhang ${ }^{\dagger}$ and Feng Liu * \\ State Key Laboratory of Solidification Processing, Northwestern Polytechnical University, \\ Xi'an 710072, Shaanxi, China; yazhu.ma@gmx.de (Y.M.); zyb@mail.nwpu.edu.cn (Y.Z.) \\ * Correspondence: liufeng@nwpu.edu.cn \\ t These authors contributed equally to this work.
}

check for updates

Citation: Ma, Y.; Zhang, Y.; Liu, F. A Non-Isokinetic Approach for Modeling Solid-State Transformations: Application to Crystallization of a Fe-B Amorphous Alloy. Materials 2021, 14, 292. https://doi.org/10.3390/ma14020292

Received: 23 November 2020

Accepted: 4 January 2021

Published: 8 January 2021

Publisher's Note: MDPI stays neutral with regard to jurisdictional clai$\mathrm{ms}$ in published maps and institutional affiliations.

Copyright: (C) 2021 by the authors. Licensee MDPI, Basel, Switzerland. This article is an open access article distributed under the terms and conditions of the Creative Commons Attribution (CC BY) license (https:// creativecommons.org/licenses/by/ $4.0 /)$.

\begin{abstract}
Solid-state phase transformations like crystallization of amorphous alloys can be described by an analytical model incorporating a nucleation index $a$. However, this model cannot be used to examine isochronal transformations with abrupt changing of enthalpy differences performed with differential scanning calorimetry. Based on the model, a non-isokinetic approach is proposed and applied to analyze the isochronal crystallization kinetics of $\mathrm{Fe}_{85} \mathrm{~B}_{15}$ amorphous alloy. The approach enabled us to obtain the kinetic parameters and activation energies for nucleation and growth.
\end{abstract}

Keywords: isochronal transformation; non-isokinetic; crystallization; Fe-B alloy

\section{Introduction}

Crystallization is usually studied using Johnson-Mehl-Avrami (JMA) kinetics [1-10]. The classical JMA equation is applied in the kinetic analysis since constant kinetic parameters can be applied to study a series of isothermal transformations carried out at different temperatures $[5,6]$ or isochronal transformations carried out with varying rates of heating [7-10]. Kinetic model parameters and impingement mode are not relevant to the annealing temperature for isothermal transformations, or to the heating rate $\Phi$ for isochronal transformations. The model parameters including the rate constant $K_{0}$, the Avrami/growth exponent $n$ and the effective activation energy $Q$ are constant by using the JMA equation $[5,6,10]$. Isokinetics means that the mechanisms of nucleation, growth and impingement are constant upon transformations, although, in general, the isokinetic approximation does not hold in the framework of the JMA model [11-14].

An analytical phase transformation model was proposed by Liu et al. [15-24], where nucleation, growth mechanisms and impingent mode are integrated. The model has been used to interpret various solid-state transformations like crystallization of amorphous alloys [16-18,23] and is deduced within the framework of the JMA equation [15-19], but the kinetic parameters $n, Q, K_{0}$ depend on time for isothermal transformations, and on temperature for isochronal transformations. Both are affected by parameters such as the nucleation and growth activation energy, $Q_{N}$ and $Q_{G}$. For a case where the nucleation rate increases with crystallization progress, a nucleation index $a[19,25,26]$ is introduced into the analytical transformation model. For $a>1$, the nucleation rate does not remain constant but increases throughout the transformation [27-30].

The analytical model is based on the extended isokinetic theory. The mechanism (such as nucleation, growth and impingement) stays the same as transformation progresses, despite the change of the model parameters. As such, $n$ changes as a function of temperature [25] (for the isothermal case) or of heating rate [31,32] (for the isochronal case). With a constant $a(\geq 1)$, the growth exponent $n(d / m<n<d / m+a$, where $m$ indicates the growth parameter, $m=1$ and 2 describe interface-controlled growth or volume diffusion-controlled 
growth, respectively; $d=1,2,3$ stands for the dimensionality of the growth [33]) can be used to cover the prevailing mechanism, i.e., the isokinetic assumption holds for the above transformations. For example, if $d / m=3$ and $a=1$, the prevailing mechanism changes between a mixture of site saturation and interface-controlled growth $(d / m=3 / 1)$ and a combination of continuous nucleation and this growth mechanism; if $d / m=1.5$ and $a=3$, the prevailing mechanism changes between a mixture of site saturation and volume diffusion-controlled growth $(d / m=3 / 2)$ and a combination of continuous nucleation with increasing nucleation rate and volume diffusion-controlled growth. The constant $a$ implies that the continuous nucleation follows an analogous increasing tendency, independent of the heating rate.

Now, a question arises about the transformations if the value of $a$ changes with the heating rate. It was found that, for isochronal transformations conducted with a wide range of heating rates, the enthalpy difference curves recorded by differential scanning calorimetry (DSC) change abruptly. The Avrami exponent does not change as assumed by the analytical model $(d / m<n<d / m+a$ with a single constant $a$ [34]), which cannot describe the prevailing mechanisms. The crystallization DSC curves of some Fe-B amorphous alloys belong to this kind of transformation. In the present work, arising from the analytical model, an analytical approach based on the non-isokinetic analysis is proposed to study the crystallization kinetics of amorphous $\mathrm{Fe}_{85} \mathrm{~B}_{15}$ alloy using isochronal annealing and DSC simultaneously.

\section{Theoretical Background}

\subsection{Transformation Rate}

Based on the analysis transformation model [15-24], for isochronal transformations with $n, Q$ and $K_{0}$ as constants (i.e., not affected by temperature $T$ ), the transformation rate $d f / d T$ follows [35]:

$$
\frac{d f}{d T}=\frac{1}{\Phi} \frac{d f}{d t}=\left(\frac{n Q}{R T^{2}}+\frac{2 n}{T}\right) I x_{e}
$$

where $f$ stands for the real transformed fraction, $R$ means the gas constant, $x_{e}$ represents the extended transformed fraction and I stands for the impingement mode [35]. The function between $f$ and $x_{e}$ depends on the impingement mode [19,35]. In comparison to the case with random nuclei dispersion $\left(I=d f / d x_{e}=1-f\right)[4,19]$, the impingement induced by anisotropic growth is more intense with $I=(1-f)^{\xi}[19,35]$, whereas the impingement according to non-randomly dispersed nuclei is less strong with $I=\left(1-f^{\varepsilon}\right)[19,35]$. Both $\xi$ and $\varepsilon$ are constant factors larger than 1 .

Usually, the condition $2 n / T<<Q / R T^{2}$ always holds, hence the set $2 n / T$ can be neglected in Equation (1) [33]. Then, it follows that

$$
\frac{d f}{d T}=\frac{1}{\Phi} \frac{d f}{d t}=\frac{n Q}{R T^{2}} I x_{e}
$$

where $t$ represents the time and $\Phi$ stands for the heating rate.

Following the analytical model, for an isochronal transformation, its rate can be obtained by [35]:

$$
\frac{d f}{d T}=\frac{1}{\Phi} \frac{d f}{d t}=\frac{n Q}{\Phi} I(f)\left[x_{e}(f)\right]^{1-\frac{1}{n}} K_{0} \exp \left(-\frac{Q}{R T}\right)
$$

Explicit expressions for $x_{e}, n, Q$ and $I$ are provided in Tables 1 and 2 in Reference [19].

\subsection{Non-Isokinetic Analysis}

Generally, the transformed fraction $f$ and the transformation rate $d f$ / $d T$ can be directly obtained from DSC measurements. Applying the maximum peak analysis for a single DSC curve yields information on the impingement [35]. The application of Equation (2) to the DSC curve directly yields the value of $n Q$. Section 4.3 shows that the isokinetic approach to 
deduce $n Q$ is the prerequisite for the subsequent non-isokinetic analysis. For other methods to deduce $n Q$, see Appendix A.

An equivalent, constant growth exponent $n$ holds for every single transformation and is given according to the following equation [36-39] (irrespective of whether it proceeds according to continuous, site saturation or mixed nucleation mechanisms [18]):

$$
n=\frac{d}{m}+a
$$

Therefore, for a series of isochronal transformations, the value of $a$ described by nonisokinetics changes with the heating rate.

For any typical nucleation-growth transformation, the following equation holds [24]:

$$
Q=\frac{\frac{d}{m} \cdot Q_{G}+\left(n-\frac{d}{m}\right) \cdot Q_{N}}{n}=\frac{\frac{d}{m} \cdot Q_{G}+a Q_{N}}{n}
$$

where $Q_{N}$ and $Q_{G}$ represent the activation energy for nucleation and growth. Then it follows that

$$
n Q=\frac{d}{m} Q_{G}+\left(n-\frac{d}{m}\right) Q_{N}
$$

On this basis, combination with Equations (3) and (5) leads to

$$
\begin{aligned}
& \frac{d f}{d t}=\frac{d f}{d T} \cdot \Phi=n Q I(f)\left[x_{e}(f)\right]^{1-\frac{1}{n}} K_{0} \exp \left(-\frac{Q}{R T}\right) \\
& =\left[\frac{d}{m} Q_{G}+\left(n-\frac{d}{m}\right) Q_{N}\right] I(f)\left[x_{e}(f)\right]^{1-\frac{1}{n}} K_{0} \exp \left(-\frac{Q}{R T}\right)
\end{aligned}
$$

The kinetic parameters $\left(n, Q\right.$ and $\left.K_{0}\right)$, as well as $Q_{N}$ and $Q_{G}$, can be obtained by fitting of Equation (7) to a series of isochronal DSC curves, in combination with the $n Q$ values deduced from Equation (2), (see Section 4.3).

\section{Materials and Methods}

$\mathrm{Fe}_{85} \mathrm{~B}_{15}$ master alloys were obtained by the induction melting of bulk high-purity iron and an inter-alloy of iron-boron under a protective argon atmosphere. A melt spinning technique with argon atmosphere was used to prepare amorphous ribbons. The thickness of the ribbons was about $32 \mu \mathrm{m}$. X-ray diffraction (XRD) (Panalytical, Almelo, The Netherlands) and transmission electron microscope (TEM) (Tecnai F30 G², FEI Company, Hillsboro, OR, United States) were applied to verify the amorphous nature of the prepared samples. Inductively coupled plasma (ICP) optical emission spectrometry technique was utilized to test the composition of the resulting ribbons; the chemical composition of the asprepared ribbons was $96.5 \pm 0.2 \mathrm{wt} . \% \mathrm{Fe}$ and $3.5 \pm 0.2 \mathrm{wt} . \% \mathrm{~B}$, and the weight composition of $\mathrm{Fe}_{85} \mathrm{~B}_{15}$ alloy comprised $96.7 \mathrm{wt} . \% \mathrm{Fe}$ and $3.3 \mathrm{wt} . \% \mathrm{~B}$.

Differential scanning calorimeter (DSC) measurements were performed during the annealing of the amorphous alloys on a power compensated Perkin Elmer DSC-7 (PerkinElmer Inc., Waltham, MA USA). The DSC instrument with alumina sample pans and covers works under flowing high-purity argon (99.995\%). Pure In, Sn, Bi, Zn, Al and Au specimens with a weight of $10 \mathrm{mg}$ were used to calibrate the DSC. The melting temperatures and the heat of fusion of the pure samples were measured for the temperature and the heat flow calibration. Due to the small weight (about $3 \mathrm{mg}$ ) of the ribbons during annealing, an empty alumina pan with a cover was used as a reference.

The ribbons were annealed isochronally using different heating rates of 5, 10, 20, 30 and $40 \mathrm{~K} \mathrm{~min}^{-1}$. The annealing at each heating rate was performed twice. During the first run, the crystallization transformation from amorphous to crystalline of the sample occurs. The second run shows whether the crystallization was completely accomplished and is further used as baseline. The curve of the transformation's enthalpy change is obtained by subtracting the second run from the first run. 
Phase analysis was accomplished on an X'pert Pro MRD diffractometer (Co-K $\alpha$ radiation, Panalytical, Almelo, The Netherlands) between $30^{\circ}$ and $120^{\circ}$ (2 $\theta$ value) with an interval of $0.04^{\circ}$. The preparation of TEM samples was performed using argon ion milling on a Gatan model 691 with an incidence angle of $13.5^{\circ}$ and $3.5 \mathrm{kV}$ acceleration voltage. The investigation of the microstructure of the annealed samples was carried out by applying a Tecnai F30 $\mathrm{G}^{2}$ TEM with an accelerating voltage of $140 \mathrm{kV}$.

\section{Results and Discussion}

\subsection{Amorphous Structure}

XRD was performed to verify the amorphous structure and determine the crystallization product. The side of the ribbons in contact with the copper roller appears dull while the opposite (free) side is shiny. However, both the dull and the shiny side show the same XRD diffraction patterns (Figure 1a). A broad pattern can be observed in the X-ray diffractogram. The as-prepared ribbon was examined by TEM. The bright field image (Figure $1 \mathrm{~b}$ ) and the selected area electron diffraction pattern (SAEDP, Figure 1c) evidence that the as-quenched structure is entirely amorphous.
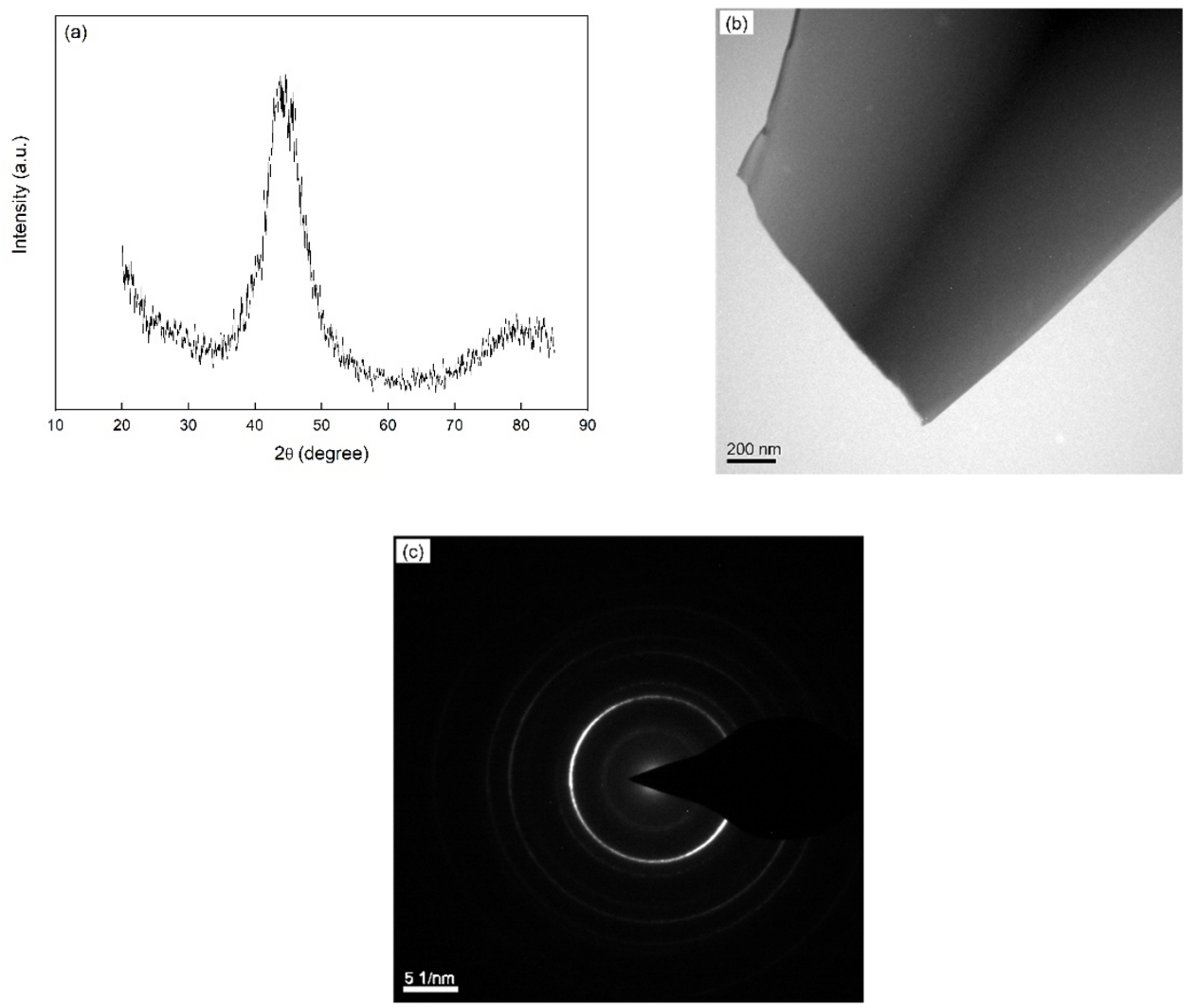

Figure 1. (a) X-ray diffraction pattern (Co-K $\alpha$ radiation), (b) TEM bright field image and (c) the corresponding selected area electron diffraction pattern (SAEDP) of the amorphous as-prepared $\mathrm{Fe}_{85} \mathrm{~B}_{15}$ alloy. The XRD and TEM investigations were carried out at room temperature.

\subsection{Crystallization Product}

The sample annealed with a heating rate of $5 \mathrm{~K} \mathrm{~min}^{-1}$ in the DSC equipment was studied using XRD, and two phases, $\alpha$-Fe (Powder Diffraction File, i.e., PDF with the number 06-0696) and tetragonal $\mathrm{Fe}_{3} \mathrm{~B}$ (PDF: 39-1315), can be found in the X-ray diffractogram (Figure 2). The phase detection was performed utilizing MDI Jade 6.0 software. The result of the crystallization product is comparable with that in $[40,41]$, in which $\alpha$-Fe and tetragonal $\mathrm{Fe}_{3} \mathrm{~B}$ were reported for $\mathrm{Fe}-\mathrm{B}$ alloys with the boron composition between 14 at. $\%$ and 25 at. $\%$. 


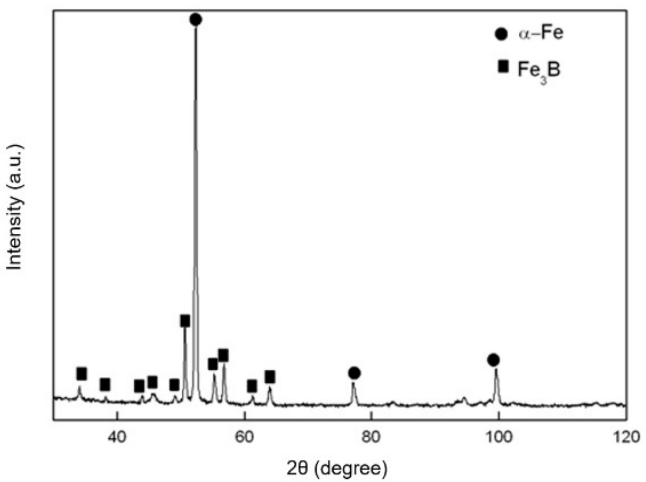

Figure 2. XRD profile for the crystallized $\mathrm{Fe}_{85} \mathrm{~B}_{15}$ alloy annealed at a rate $5 \mathrm{~K} \mathrm{~min}^{-1}$. The crystalline in the alloy was detected as $\alpha$-Fe (PDF number: 06-0696) and tetragonal $\mathrm{Fe}_{3} \mathrm{~B}$ (PDF number: 39-1315) by applying the MDI Jade 6.0 program.

The samples annealed with $\Phi=5,20$ and $40 \mathrm{~K} \mathrm{~min}^{-1}$ were investigated using TEM (Figure 3). Nano-scaled grains with an approximately globular shape can be observed in the TEM bright field images (Figure 3a,c,e). In the corresponding SAEDPs (Figure 3b,d,f), numerous spots are present and aligned in circles because of the characteristic of the nanosized microstructure. The diameter of the circles with diffraction spots can be assigned to the $\alpha$-Fe and tetragonal $\mathrm{Fe}_{3} \mathrm{~B}$ phases, which correspond to the XRD result. The particles in the crystallized specimens observed in the bright field images (Figure 3a,c,e) contain two phases, i.e., pure particles of either $\alpha$-Fe phase or $\mathrm{Fe}_{3} \mathrm{~B}$ phase cannot be found.
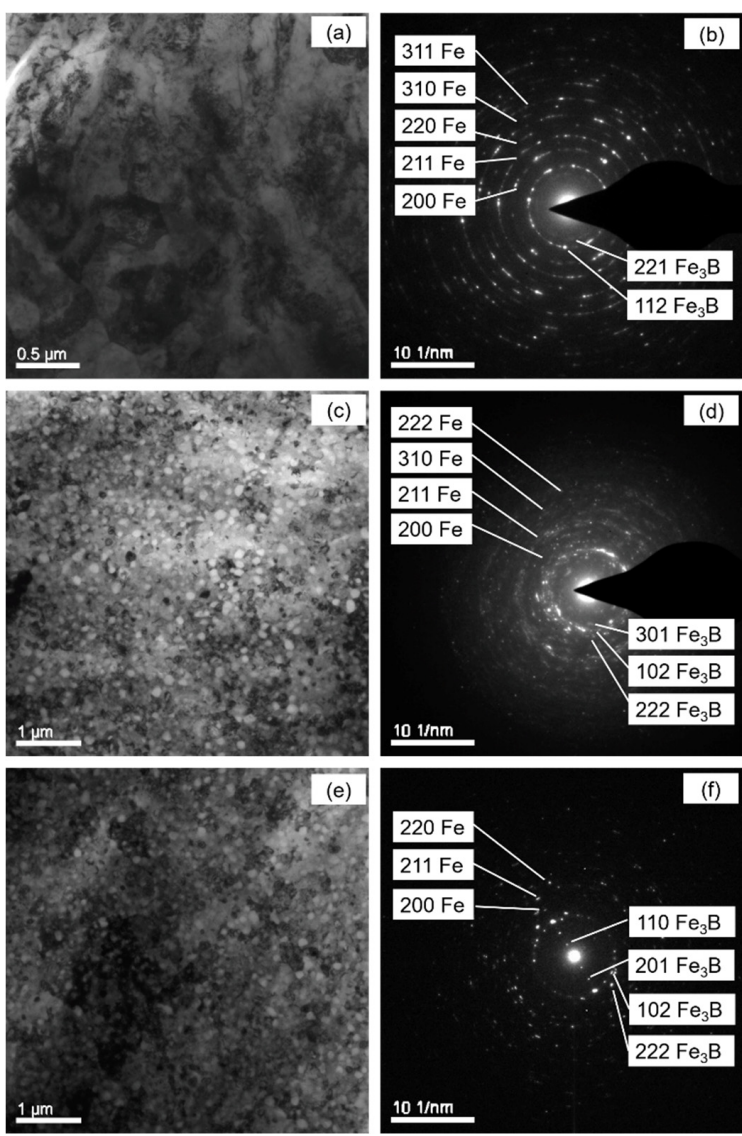

Figure 3. Bright field micrograph of TEM and SAEDPs of the crystallized $\mathrm{Fe}_{85} \mathrm{~B}_{15}$ amorphous alloy after heated at $5 \mathrm{~K} \mathrm{~min}^{-1}\left((\mathbf{a})\right.$ and (b)); at $20 \mathrm{~K} \mathrm{~min}^{-1}((\mathbf{c})$ and $(\mathbf{d}))$ and at $40 \mathrm{~K} \mathrm{~min}^{-1}((\mathbf{e})$ and (f)). The diameter for $\alpha$-Fe (bcc) and tetragonal $\mathrm{Fe}_{3} \mathrm{~B}$ phases have been identified in the SAEDPs $(\mathbf{b}, \mathbf{d}, \mathbf{f})$. 


\subsection{Crystallization Kinetics}

The isochronal DSC scans for the crystallization of amorphous $\mathrm{Fe}_{85} \mathrm{~B}_{15}$ ribbons were recorded at different heating rates of 5, 10, 20,30 and $40 \mathrm{~K} \mathrm{~min}^{-1}$. One single exothermic peak appears in the DSC measurements due to the crystallization reaction (Figure 4a). The XRD and TEM analyses show that two phases are present after the crystallization. Therefore, the two phases are formed in one step during the crystallization of $\mathrm{Fe}_{85} \mathrm{~B}_{15}$ alloy, in which both phases grow simultaneously. The rate of the enthalpy difference $d \Delta H / d t$ during the crystallization can be obtained after performing the baseline correction [42], in which $\Delta H$ represents the enthalpy difference in crystallization with a negative value. The transformed fraction $f$ is defined as the ratio of the enthalpy change $\Delta H$ to the total crystallization enthalpy $\Delta H_{\text {tot }}$, as determined from the DSC experiments, i.e., $f=\Delta H / \Delta H_{\text {tot }}$. The baseline-corrected isochronal DSC scans are depicted in Figure $4 \mathrm{a}$. The averaged total crystallization enthalpy subjected to different heating rates is about $168 \pm 3 \mathrm{~J} \mathrm{~g}^{-1}$ according to Figure $4 \mathrm{a}$, which is in agreement with the data in $[43,44]$. The obtained transformed fraction $f$ vs. temperature is reproduced in Figure $4 \mathrm{~b}$. In Figure $4 \mathrm{c}$, the evolution of the transformation rate $d f / d T$ with $f$ is represented.

The temperature at the peak of the transformation rate increases with increasing $\Phi$, accompanied by a simultaneous increase in the maximum transformation rate (Figures $4 \mathrm{c}$ and 5 ). This observation indicates that the transformation follows non-isokinetics (i.e., abnormal growth exponent occurs upon increasing $\Phi$; see Section 2.2). Otherwise, the transformation rate according to Equation (2) would decrease monotonically with increasing $\Phi[15,19]$. The kinetic parameters $n, Q$ and $K_{0}$, as well as the impingement mode, are obtained by fitting the isochronally conducted transformations by utilizing Equation (7).
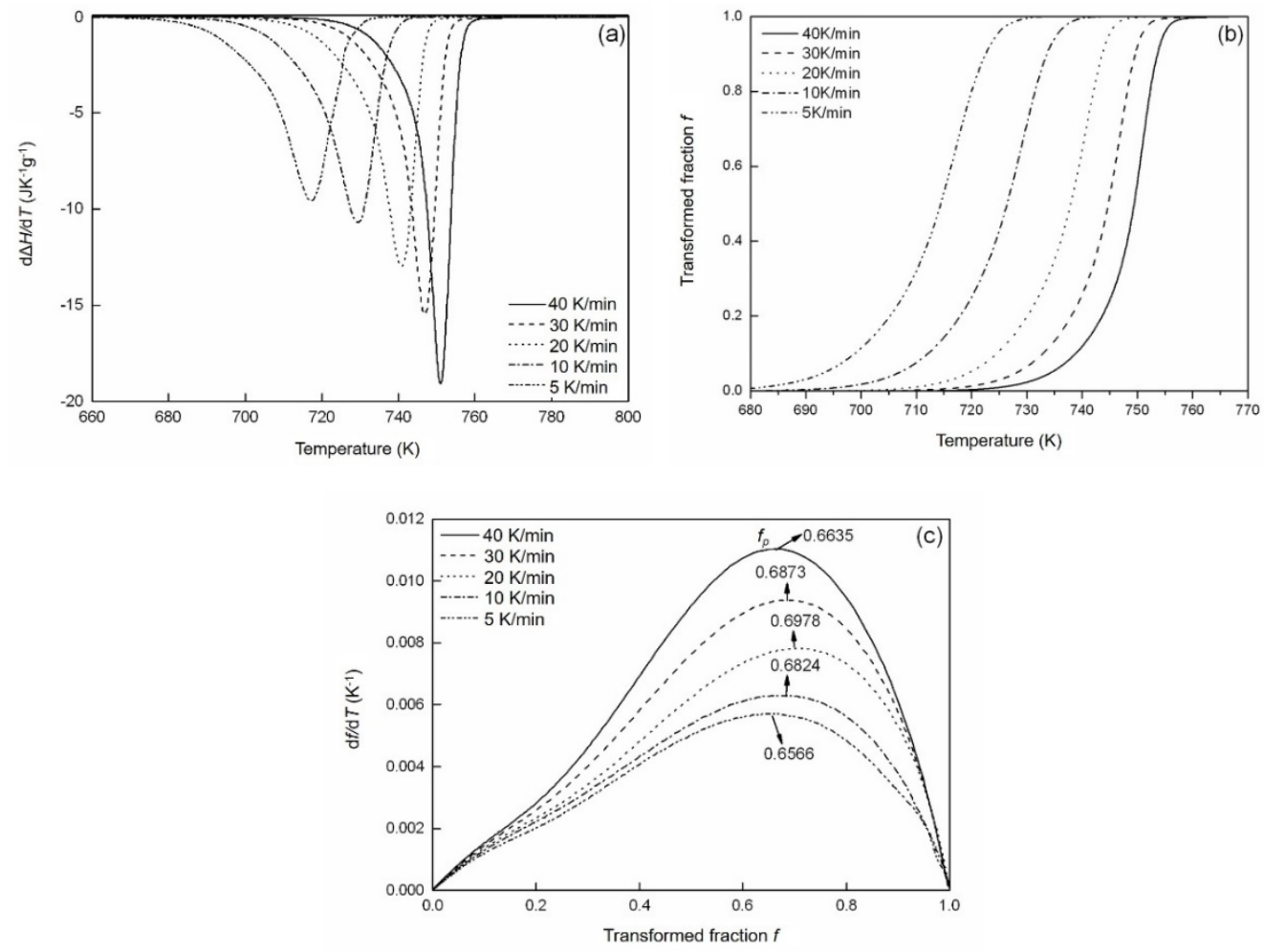

Figure 4. (a) Rate of enthalpy change divided by the heating rate $d \Delta H / \Phi d t=d \Delta H / d T$, (b) evolution of transformed fraction $f$ with temperature $T$ and (c) evolution of $d f / d T$ (transformation rate) with transformed fraction $f$, derived from differential scanning calorimetry (DSC) measurement of the amorphous $\mathrm{Fe}_{85} \mathrm{~B}_{15}$ alloy after being isochronally crystallized, with heating rates $\Phi$ of 5, 10, 20, 30 and $40 \mathrm{~K} \mathrm{~min}^{-1}$. The values of $f_{p}$ are larger than $1-1 / \mathrm{e}(\mathbf{c})$. 
Table 1. Kinetic parameters $n, Q, K_{0}$, nucleation index $a$ and impingement factor $\varepsilon$, as determined by fitting the measured DSC curves using the current model for the isochronally crystallized amorphous $\mathrm{Fe}_{85} \mathrm{~B}_{15}$ alloy (see Section 4.3), with the initial assumed values $n=4, K_{0}=1 \times 10^{9} \mathrm{~s}^{-1}, Q=300 \mathrm{~kJ} \mathrm{~mol}^{-1}$ during fitting.

\begin{tabular}{ccccccc}
\hline $\boldsymbol{\Phi}\left(\mathbf{K ~ m i n ~}^{-\mathbf{1}}\right)$ & $\boldsymbol{n}$ & $\boldsymbol{Q}\left(\mathbf{k J ~ \mathbf { ~ m o l } ^ { - \mathbf { 1 } } )}\right.$ & $\boldsymbol{K}_{\mathbf{0}}\left(\mathbf{s}^{-\mathbf{1}}\right)$ & $\boldsymbol{\varepsilon}$ & $\boldsymbol{a}$ & Error $(\mathbf{\%})$ \\
\hline 5 & 2.61 & 236.9 & $2.8 \times 10^{8}$ & 1.88 & 1.11 & 4.68 \\
10 & 2.90 & 252.0 & $3.1 \times 10^{9}$ & 2.23 & 1.40 & 1.83 \\
20 & 3.52 & 264.8 & $2.2 \times 10^{10}$ & 3.72 & 2.02 & 6.61 \\
30 & 4.60 & 268.8 & $4.2 \times 10^{10}$ & 3.28 & 3.08 & 4.81 \\
40 & 6.75 & 272.1 & $6.1 \times 10^{10}$ & 2.75 & 5.25 & 2.74 \\
\hline
\end{tabular}

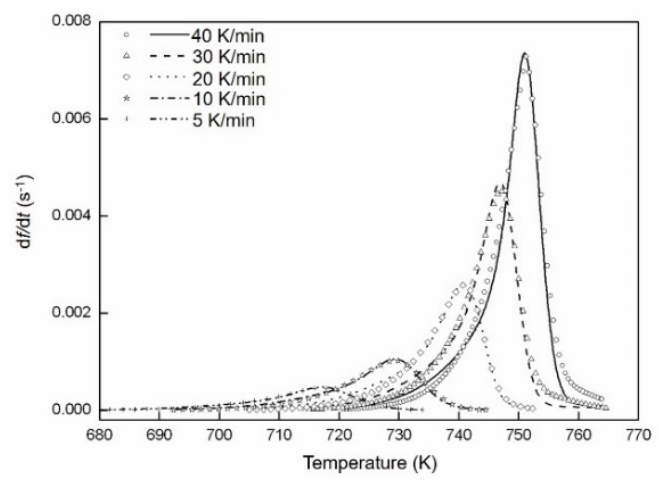

Figure 5. The transformation rate due to isochronal crystallization of amorphous $\mathrm{Fe}_{85} \mathrm{~B}_{15}$ alloy at the heating rates indicated, as measured by DSC (lines), and as fitted by the current model (symbols). The fitting result from Equation (7) of heating rates 5, 10, 20, 30 and $40 \mathrm{~K} \mathrm{~min}^{-1}$. The fitting parameters obtained are given in Table 1.

For isochronal transformations, the transformed fraction at the peak of the transformation rate, i.e., $f_{p}$ does not depend on the value of $n$ [35]. As exhibited in Figure 4c, the impingement according to non-random dispersed nuclei (with the impingement factor $\varepsilon>1$ [28]) results from $f_{p}>1-1$ /e [28]. In the current mode, $\varepsilon$ is chosen as a fitting parameter in the fitting of the transformation curves.

As shown in Section 2.2, for every single transformation, the product of $n Q$ can be calculated according to Equation (A7) with the experimental DSC data points at the peak maximum of the transformation curves, about $618.33,730.86,932.20,1236.25$ and $1836.54 \mathrm{~kJ} \mathrm{~mol}^{-1}$, respectively, for heating rates from $5 \mathrm{~K} \mathrm{~min}^{-1}$ to $40 \mathrm{~K} \mathrm{~min}^{-1}$. Using Equation (7) and the impingement mode deduced above, the evolution of $d f / d t$ according to temperature $T$ can be calculated.

The fitting was carried out by applying a downhill simplex method [45]. With adjusting the kinetic parameters $K_{0}, n$ and $\varepsilon$, the least-squares difference is obtained between the calculated values using the model and the experimentally measured curves. The quality of the fitting is given by the ratio between the total of the absolute differences (i.e., fitted $d f / d t$ values subtracted from the measured $d f / d t$ values) and the sum of all the fitted $d f / d t$ absolute values. The fitting results are reproduced in Figure 5 . The kinetic parameters $K_{0}, n$ and $\varepsilon$ determined by this analysis are summarized in Table 1 . The overall activation energy $Q$ at each heating rate can then be calculated from the values of $n Q$; the activation energies for nucleation $Q_{N}$ and growth $Q_{G}$ can be obtained according to Equation (6) (Figure 6). 


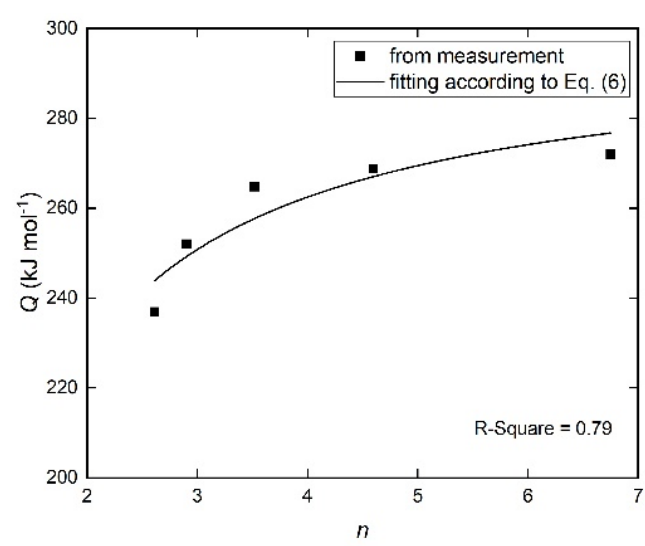

Figure 6. The evolution of the overall effective activation energy $Q$ and the Avrami (growth) exponent $n$ with heating rates of $5-40 \mathrm{~K} \mathrm{~min}^{-1}$. The separate activation energy for nucleation and growth is obtained by fitting Equation (6) to the data points with $n$ and $Q$ values listed in Table 1 . The result is $Q_{N}=297 \pm 10 \mathrm{~kJ} \mathrm{~mol}^{-1}, Q_{G}=204 \pm 33 \mathrm{~kJ} \mathrm{~mol}^{-1}$, with an R-square value of about 0.79 .

As shown in Table 1, the growth exponent $n$ is fitted as values increasing from $\sim 2.6$ to $\sim 6.8$ with increasing $\Phi$, thus indicating that the transformation follows non-isokinetics (i.e., $a$ is accordingly changing with the heating rate). In combination with Section 4.2, the crystallization is therefore controlled by mixed nucleation with the nucleation index $a$, volume diffusion-controlled growth in three dimensions (i.e., $d=3$ and $m=2$; see Equation (7)) and impingement mode according to non-randomly dispersed nuclei. This is supported by the microstructure after crystallization (Figure 3). The growth mode corresponds to the formation of two new phases from the amorphous matrix during crystallization (Section 4.2).

As shown in Figure 6, the activation energies for nucleation $Q_{N}$ and growth $Q_{G}$ during the transformation are deduced as $297 \pm 10 \mathrm{~kJ} \mathrm{~mol}^{-1}$ and $204 \pm 33 \mathrm{~kJ} \mathrm{~mol}^{-1}$, respectively. These data can be compared with the diffusion data of crystalline ironboron alloys: the activation energy for boron diffusion in $\alpha$-iron provided by Busby et al. [46-48] is $Q=260 \mathrm{~kJ} \mathrm{~mol}^{-1}$; the activation energy for self-diffusion of Fe in $\alpha$-iron is $Q \approx 239.7 \mathrm{~kJ} \mathrm{~mol}^{-1}$ [49]. Accordingly, the obtained result for $Q_{G}$ is reasonable. The value for $Q_{N}\left(297 \pm 10 \mathrm{~kJ} \mathrm{~mol}^{-1}\right)$ is almost the same as the nucleation activation energy values obtained for metal-metalloid glasses $\left(\mathrm{Fe}_{65} \mathrm{Ni}_{10} \mathrm{~B}_{25}: 300 \mathrm{~kJ} \mathrm{~mol}^{-1}\right.$ [50]). The result for $Q_{N}$ can be therefore considered plausible as well.

The crystalline after crystallizations with $\Phi=5,20,40 \mathrm{~K} \mathrm{~min}^{-1}$ are represented in Figure $7 \mathrm{a}-\mathrm{c}$. The average grain size of the crystalline can be calculated using the linear intercept method (Figure 7d). Its diameter decreases from $\sim 400 \mathrm{~nm}$ to $\sim 100 \mathrm{~nm}$ when $\Phi$ increases from $5 \mathrm{~K} \mathrm{~min}^{-1}$ to $40 \mathrm{~K} \mathrm{~min}^{-1}$, suggesting a strong heating rate dependence of the as-crystallized grain size. This is compatible with the acceleration of the nucleation rate because of a progressing transformation during isochronal crystallization $(a=5.25$ for $\Phi=40 \mathrm{~K} \mathrm{~min}^{-1}$ and $a=1.11$ for $\Phi=5 \mathrm{~K} \mathrm{~min}^{-1}$ ). The higher value of the index $a$ indicates the highly increased nucleation rate upon crystallization with a higher heating rate. 

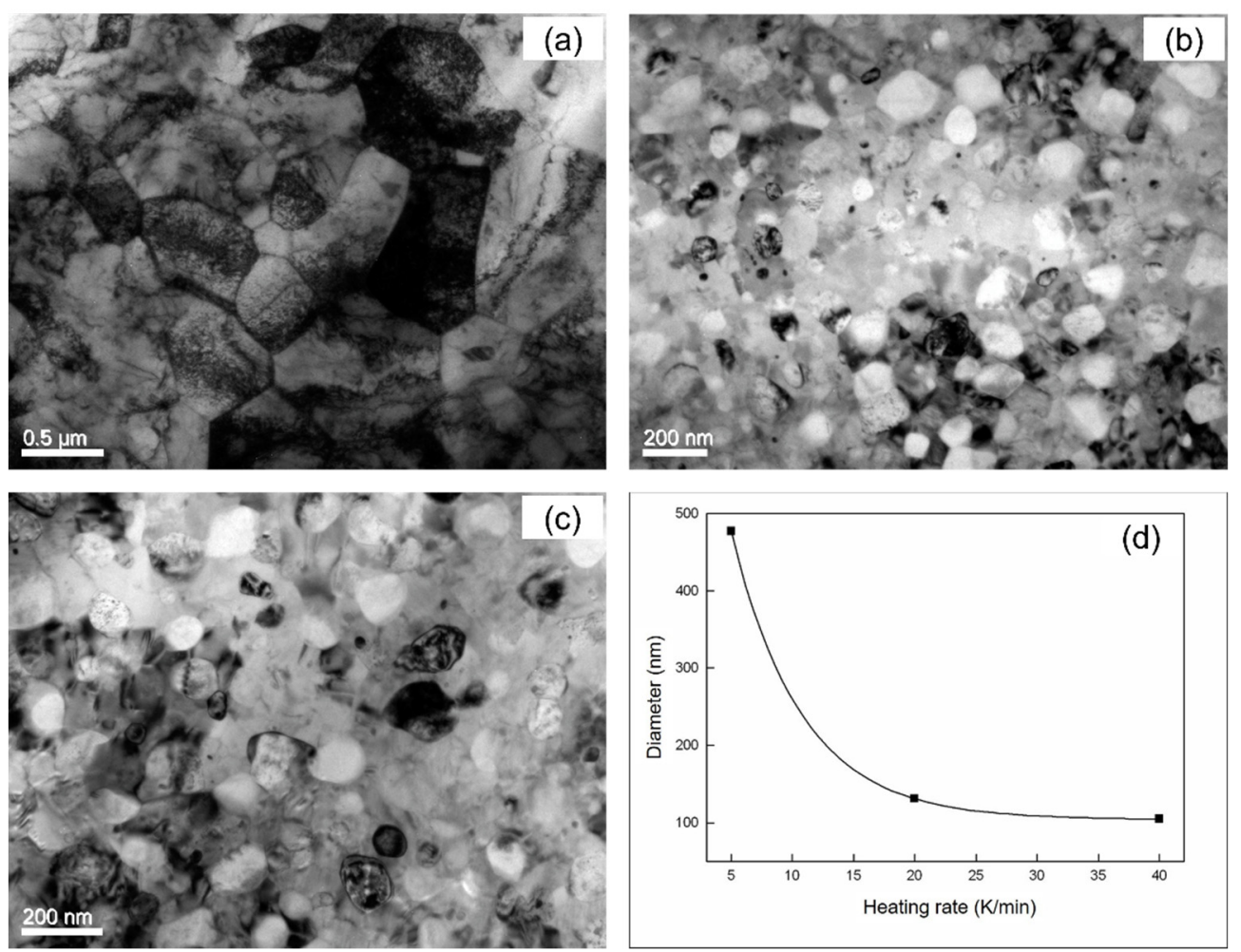

Figure 7. Bright field micrograph of TEM of the crystallized $\mathrm{Fe}_{85} \mathrm{~B}_{15}$ alloy annealed at the heating rates of $5 \mathrm{~K}$ min ${ }^{-1}$ (a), $20 \mathrm{~K} \mathrm{~min}^{-1}$ (b) and $40 \mathrm{~K} \mathrm{~min}^{-1}$ (c). (d) The average crystal size after crystallization at the heating rates of 5, 20 and $40 \mathrm{~K}$ $\mathrm{min}^{-1}$ has been calculated with linear intercept method accordingly (symbols). The line is drawn as a guide to the eye.

\section{Conclusions}

A non-isokinetic approach has been performed to study transformations with abrupt changing of DSC peaks for isochronally conducted transformation. Accordingly, the growth exponent $n$ and the effective activation energy $Q$ of a series of isochronal transformations can be quantitatively described. The following conclusions can be drawn:

(1) A different analytical model based on non-isokinetics was proposed to describe real transformations with a growth exponent $d / m<n<d / m+a$. As such, the kinetic parameters controlling crystallization of amorphous $\mathrm{Fe}_{85} \mathrm{~B}_{15}$ alloys were obtained. These are compatible with a decreasing average grain size with increasing heating rates, because of the increasing nucleation rate.

(2) The isochronal crystallization of the $\mathrm{Fe}_{85} \mathrm{~B}_{15}$ amorphous alloy is controlled by mixed nucleation including nucleation index, $a$, three-dimensional volume diffusion-controlled growth (i.e., $d=3$ and $m=2$ ) and impingement mode due to non-randomly dispersed nuclei.

(3) The isochronally crystallized product was investigated by applying XRD and TEM. The nanosized particles contain two phases, i.e., $\alpha$-Fe and $\mathrm{Fe}_{3} \mathrm{~B}$.

(4) By applying the current analytical model to the isochronal crystallization of $\mathrm{Fe}_{85} \mathrm{~B}_{15}$, reasonable values for the activation energies of nucleation $\left(Q_{N}=297 \pm 10 \mathrm{~kJ} \mathrm{~mol}^{-1}\right)$ and growth $\left(Q_{G}=204 \pm 33 \mathrm{~kJ} \mathrm{~mol}^{-1}\right)$ were obtained.

Author Contributions: Conceptualization, Y.M. and F.L.; methodology, Y.M. and Y.Z.; Discussion, Y.M and Y.Z.; validation, F.L.; formal analysis, F.L.; investigation and analysis, Y.M. and Y.Z.; writingoriginal draft preparation, Y.M. and Y.Z.; writing—review and editing, F.L.; supervision, F.L.; project administration, F.L.; funding acquisition, F.L. All authors have read and agreed to the published version of the manuscript.

Funding: This research was funded by the National Key Research and Development Program of China (Nos. 2017YFB0703001, 2017YFB0305100), the National Natural Science Foundation of 
China (Nos. 51134011, 51431008, 51790481) and the Fundamental Research Funds for the Central Universities (No. 3102017jc01002).

Data Availability Statement: The data presented in this study are available on request from the corresponding author. The data are not publicly available at this time due to the data also forms part of an ongoing study.

Conflicts of Interest: The authors declare no conflict of interest.

\section{Appendix A}

Generally, the peak of the DSC curve corresponds to the maximum transformation rate, i.e., $d^{2} f / d T^{2}=0$. When the impingement mode is according to random nuclei dispersion, the following condition must be satisfied at the peak [35]:

$$
0=\left[1+\ln \left(1-f_{p}\right)\right]
$$

Assume the temperature of peak maximum as $T_{p}$, then [35]

$$
\frac{\Phi}{T_{p}^{2}}=R K_{0} \exp \left(-\frac{Q_{p}}{R T_{p}}\right)
$$

Given $K=K_{0} \exp \left(-\frac{Q}{R T}\right)$, then this results in $K_{p}=K_{0} \exp \left(-\frac{Q_{p}}{R T_{p}}\right)$.

Subsequently,

$$
\frac{K}{K_{p}}=\exp \left(\frac{T Q_{p}-T_{p} Q}{R T T_{p}}\right)
$$

where $\frac{K}{K_{p}} \cong \exp \left(\frac{Q}{R T_{p}^{2}}\left(T-T_{p}\right)\right)$ approximately.

Following [51], where the basic assumptions $\left(T-T_{p}=\Phi t\right.$ and $\left.\frac{K}{K_{p}}=\exp \left(\frac{Q}{R} \frac{\Phi t}{T_{p}^{2}}\right)\right)$ are made, this results in

$$
K=K_{0} \exp \left(-\frac{Q_{p}}{R T_{p}}\right) \exp \left(Q K_{0} \exp \left(-\frac{Q_{p}}{R T}\right) t\right)
$$

Assuming $t^{\prime}=t\left[\exp \left(-\frac{Q_{p}}{R T}\right)\right]$ leads to

$$
\frac{d x_{e}}{d t^{\prime}}=n Q K_{0}\left[x_{e}\right]^{1-\frac{1}{n}} \exp \left(Q K_{0} t^{\prime}\right)
$$

with $K_{0}=\exp \left(\frac{Q_{p}}{R T_{p}}\right) \frac{\Phi}{R T_{p}^{2}}$.

As compared to $t^{\prime}$, for the case with the impingement mode according to random nuclei dispersion and isokinetic assumption, i.e., $Q=Q_{p}$,

$$
f=1-\exp \left[-\left[\exp \left(\left(\frac{Q}{R T_{p}^{2}}\right)\left(T-T_{p}\right)\right)\right]^{n}\right]
$$

From (A6), this also results as

$$
\frac{\partial \ln (-\ln (1-f))}{\partial\left(\frac{T-T_{p}}{T_{p}{ }^{2}}\right)}=\frac{n Q}{R}
$$

\section{References}

1. Johnson, W.A.; Mehl, R.F. Reaction kinetics in proceses of nucleation and growth. Trans. Amer. Inst. Min. (Metall.) Engrs. 1939, 135, 416-458. 
2. Avrami, M. Kinetics of phase change. I General theory. J. Chem. Phys. 1939, 7, 1103-1112. [CrossRef]

3. Kolmogorov, A.N.; Shiryayev, A.N. Selected Works of AN Kolmogorov: Volume II Probability Theory and Mathematical Statistics; Springer Science \& Business Media: Berlin, Germany, 1992.

4. Christian, J.W. The Theory of Transformations in Metals and Alloys; Newnes Books of Elsevier: Amsterdam, The Netherlands, 2002.

5. Sha, W. Computer modelling of isothermal crystallisation kinetics of electroless and melt quenched amorphous solids using Johnson-Mehl-Avrami theory. Mater. Sci. Technol. 2005, 21, 69-75. [CrossRef]

6. Peixoto, E.; Mendonça, E.; Mercena, S.; Jesus, A.; Barbosa, C.; Meneses, C.; Duque, J.; Da Silva, R.A.G. Study of the dynamic of crystallization of an amorphous $\mathrm{Fe}_{40} \mathrm{Ni}_{40} \mathrm{P}_{14} \mathrm{~B}_{6}$ ribbon through Johnson-Mehl-Avrami model. J. Alloy Compd. 2018, 731, 1275-1279. [CrossRef]

7. Tavoosi, M.; Karimzadeh, F.; Enayati, M.H.; Lee, S.; Kim, H.S. Kinetic study of non-isothermal crystallization in $\mathrm{Al}_{80} \mathrm{Fe}_{10} \mathrm{Ti}_{5} \mathrm{Ni}_{5}$ metallic glass. Met. Mater. Int. 2013, 19, 901-906. [CrossRef]

8. Svoboda, R.; Málek, J. Non-isothermal crystallization kinetics of $\mathrm{As}_{2} \mathrm{Se}_{3}$ glass studied by DSC. Thermochim. Acta 2014, 579, 56-63. [CrossRef]

9. Farjas, J.; Roura, P. Modification of the Kolmogorov-Johnson-Mehl-Avrami rate equation for non-isothermal experiments and its analytical solution. Acta Mater. 2006, 54, 5573-5579. [CrossRef]

10. Adelfar, R.; Mirzadeh, H.; Ataie, A.; Malekan, M. Crystallization kinetics of mechanically alloyed amorphous Fe-Ti alloys during annealing. Adv. Powder Technol. 2020, 31, 3215-3221. [CrossRef]

11. Yinnon, H.; Uhlmann, D. Applications of thermoanalytical techniques to the study of crystallization kinetics in glass-forming liquids, part I: Theory. J. Non-Cryst. Solids 1983, 54, 253-275. [CrossRef]

12. Henderson, D.W. Experimental analysis of non-isothermal transformations involving nucleation and growth. J. Therm. Anal. Calorim. 1979, 15, 325-331. [CrossRef]

13. De Bruijn, T.; De Jong, W.; Berg, P.V.D. Kinetic parameters in Avrami-Erofeev type reactions from isothermal and non-isothermal experiments. Thermochim. Acta 1981, 45, 315-325. [CrossRef]

14. Rashidi, R.; Malekan, M.; Gholamipour, R. Crystallization kinetics of $\mathrm{Cu}_{47} \mathrm{Zr}_{47} \mathrm{~A}_{16}$ and $\left(\mathrm{Cu}_{47} \mathrm{Zr}_{47} \mathrm{~A}_{16}\right)_{99} \mathrm{Sn}_{1}$ bulk metallic glasses. J. Non-Cryst. Solids 2018, 498, 272-280. [CrossRef]

15. Liu, F.; Sommer, F.; Mittemeijer, E.J. An analytical model for isothermal and isochronal transformation kinetics. J. Mater. Sci. 2004, 39, 1621-1634. [CrossRef]

16. Liu, F.; Sommer, F.; Mittemeijer, E. Parameter determination of an analytical model for phase transformation kinetics: Application to crystallization of amorphous Mg-Ni alloys. J. Mater. Res. 2004, 19, 2586-2596. [CrossRef]

17. Liu, F.; Sommer, F.; Mittemeijer, E. Determination of nucleation and growth mechanisms of the crystallization of amorphous alloys; application to calorimetric data. Acta Mater. 2004, 52, 3207-3216. [CrossRef]

18. Liu, F.; Sommer, F.; Mittemeijer, E.J. Analysis of the kinetics of phase transformations; roles of nucleation index and temperature dependent site saturation, and recipes for the extraction of kinetic parameters. J. Mater. Sci. 2006, 42, 573-587. [CrossRef]

19. Liu, F.; Sommer, F.; Bos, C.; Mittemeijer, E.J. Analysis of solid state phase transformation kinetics: Models and recipes. Int. Mater. Rev. 2007, 52, 193-212. [CrossRef]

20. Liu, F.; Song, S.; Xu, J.; Wang, J. Determination of nucleation and growth modes from evaluation of transformed fraction in solid-state transformation. Acta Mater. 2008, 56, 6003-6012. [CrossRef]

21. Liu, F.; Yang, G. Effects of anisotropic growth on the deviations from Johnson-Mehl-Avrami kinetics. Acta Mater. 2007, 55, 1629-1639. [CrossRef]

22. Liu, F.; Yang, C.; Yang, G.; Zhou, Y. Additivity rule, isothermal and non-isothermal transformations on the basis of an analytical transformation model. Acta Mater. 2007, 55, 5255-5267. [CrossRef]

23. Liu, F.; Yang, G.; Liu, J. Comparison between an analytical model and JMA kinetics for isothermally and isochronally conducted transformations. Thermochim. Acta 2005, 438, 83-89. [CrossRef]

24. Liu, F.; Huang, K.; Jiang, Y.-H.; Song, S.-J.; Gu, B. Analytical description for solid-state phase transformation kinetics: Extended works from a modular model, a review. J. Mater. Sci. Technol. 2016, 32, 97-120. [CrossRef]

25. Ruitenberg, G.; Petford-Long, A.K.; Doole, R.C. Determination of the isothermal nucleation and growth parameters for the crystallization of thin $\mathrm{Ge}_{2} \mathrm{Sb}_{2} \mathrm{Te}_{5}$ films. J. Appl. Phys. 2002, 92, 3116-3123. [CrossRef]

26. Ranganathan, S.; Von Heimendahl, M. The three activation energies with isothermal transformations: Applications to metallic glasses. J. Mater. Sci. 1981, 16, 2401-2404. [CrossRef]

27. Turnbull, D. Phase changes. Methods Exp. Phys. 1956, 3, 225-306. [CrossRef]

28. Scott, M.; Ramachandrarao, P. The kinetics of crystallisation of an Fe-P-C glass. Mater. Sci. Eng. 1977, 29, 137-144. [CrossRef]

29. Shen, T.; Schwarz, R. Bulk ferromagnetic glasses in the Fe-Ni-P-B system. Acta Mater. 2001, 49, 837-847. [CrossRef]

30. Biswas, K.; Ram, S.; Schultz, L.; Eckert, J. Crystallization kinetics of amorphous $\mathrm{Fe}_{67} \mathrm{Co}_{9.5} \mathrm{Nd}_{3} \mathrm{Dy}_{0.5} \mathrm{~B}_{20}$. J. Alloy Compd. 2005, 397, 104-109. [CrossRef]

31. Blazquez, J.; Conde, C.; Conde, A. Non-isothermal approach to isokinetic crystallization processes: Application to the nanocrystallization of HITPERM alloys. Acta Mater. 2005, 53, 2305-2311. [CrossRef]

32. Kong, L.; Gao, Y.; Song, T.; Wang, G.; Zhai, Q. Non-isothermal crystallization kinetics of FeZrB amorphous alloy. Thermochim. Acta 2011, 522, 166-172. [CrossRef]

33. Mittemeijer, E.J. Analysis of the kinetics of phase transformations. J. Mater. Sci. 1992, 27, 3977-3987. [CrossRef] 
34. Zhang, H.; Mitchell, B.S. A Method for Determining Crystallization Kinetic Parameters from one Nonisothermal Calorimetric Experiment. J. Mater. Res. 2000, 15, 1000-1007. [CrossRef]

35. Liu, F.; Song, S.; Sommer, F.; Mittemeijer, E. Evaluation of the maximum transformation rate for analyzing solid-state phase transformation kinetics. Acta Mater. 2009, 57, 6176-6190. [CrossRef]

36. Ouyang, Y.; Wang, L.; Chen, H.; Cheng, X.; Zhong, X.; Feng, Y. The formation and crystallization of amorphous Al65Fe20Zr15. J. Non-Cryst. Solids 2008, 354, 5555-5558. [CrossRef]

37. Wang, Y.; Xu, K.; Li, Q. Comparative study of non-isothermal crystallization kinetics between $\mathrm{Fe}_{80} \mathrm{P}_{13} \mathrm{C}_{7}$ bulk metallic glass and melt-spun glassy ribbon. J. Alloy. Compd. 2012, 540, 6-15. [CrossRef]

38. Paul, T.; Loganathan, A.; Agarwal, A.; Harimkar, S.P. Kinetics of isochronal crystallization in a Fe-based amorphous alloy. J. Alloy Compd. 2018, 753, 679-687. [CrossRef]

39. Wu, J.; Pan, Y.; Huang, J.; Pi, J. Non-isothermal crystallization kinetics and glass-forming ability of Cu-Zr-Ti-In bulk metallic glasses. Thermochim. Acta 2013, 552, 15-22. [CrossRef]

40. Takahashi, M.; Koshimura, M.; Abuzuka, T. Phase Diagram of Amorphous and Crystallized Fe-B Alloy System. Jpn. J. Appl. Phys. 1981, 20, 1821-1832. [CrossRef]

41. Zhang, Y.; Budnick, J.; Ford, J.; Hines, W.; Sanchez, F.; Hasegawa, R. Crystallization of Fe-B amorphous alloys: A NMR and x-ray study. J. Appl. Phys. 1987, 61, 3231-3233. [CrossRef]

42. Kempen, A.; Sommer, F.; Mittemeijer, E. The isothermal and isochronal kinetics of the crystallisation of bulk amorphous Pd40Cu30P20Ni10. Acta Mater. 2002, 50, 1319-1329. [CrossRef]

43. Antonione, C.; Battezzati, L.; MARINO, F.; COCCO, G. Thermomechanical and structural investigation of crystallization in Fe-B and Fe-Si-B metallic glasses. Z. Metallk. 1984, 75, 714-718.

44. Palumbo, M.; Baricco, M. Modelling of primary bcc-Fe crystal growth in a FeB amorphous alloy. Acta Mater. 2005, 53, 2231-2239. [CrossRef]

45. Press, W.H.; Teukolsky, S.A. Numerical recipes: Does this paradigm have a future? Comput. Phys. 1997, 11, 416-424. [CrossRef]

46. Busby, P.E.; Warga, M.E.; Wells, C. Diffusion and Solubility of Boron in Iron and Steel. JOM 1953, 5, 1463-1468. [CrossRef]

47. Busby, P.E.; Wells, C. Diffusion of Boron in Alpha Iron. JOM 1954, 6, 972. [CrossRef]

48. Fors, D.H.R.; Wahnström, G. Nature of boron solution and diffusion in $\alpha$-iron. Phys. Rev. B 2008, 77, 132102. [CrossRef]

49. Al-Haj, M.; Barry, J. Nanocrystallization kinetics of $\mathrm{Fe}_{87.5} \mathrm{Zr}_{6} \mathrm{~B}_{5.5} \mathrm{~A}_{11}$ amorphous alloy. J. Mater. Sci. Lett. 1997, 16, 1640-1642. [CrossRef]

50. Köster, U.; Schünemann, U.; Blank-Bewersdorff, M.; Brauer, S.; Sutton, M.; Stephenson, G. Nanocrystalline materials by crystallization of metal-metalloid glasses. Mater. Sci. Eng. A 1991, 133, 611-615. [CrossRef]

51. Rios, P.R.; Godiksen, R.; Schmidt, S.; Jensen, D.J.; VanderMeer, R. Analytical expression for the evolution of interfacial area density between transformed grains during nucleation and growth transformations. Scr. Mater. 2006, 54, 1509-1513. [CrossRef] 